INTERNATIONAL JOURNAL OF RESEARCHES IN BIOSCIENCES, AGRICULTURE AND TECHNOLOGY (c) VISHWASHANTI MULTIPURPOSE SOCIETY (Global Peace Multipurpose Society) R. No. MH-659/13(N) www.ijrbat.in

\title{
PHYTOCHEMICAL ANALYSIS AND CHEMICAL FINGERPRINTING OF EMBELIA RIBES BURM. F.
}

\author{
Amit Saraf and AlkaChaturvedi \\ Department of Botany, RTM Nagpur University, Nagpur, India \\ aysaraf@gmail.com
}

\begin{abstract}
:
Empirical knowledge regarding the utility and efficacy of herbals is the foundation of traditional medicinal system like Ayurveda. Embelia ribes Burm. F, commonly known as vaividang, vavding or vidang, is widely used in Ayurveda for its rejuvenating property in the preparation of panchanimbadivati, sanjivanivati and chandraprabhavati. The plant is utilized for its antifertility and anthelmintic activity. It also features among highly traded plant species from India. Phytochemical standardization of such medicinally important plant was carried out as per the guidelines mentioned in WHO and various pharmacopoeias. Proximate studies and extractive values of dried fruit powder were performed to examine the suitability of crude sample. Optimization of solvent for extraction aided to improvise the HPTLC studies. HPTLC fingerprints will help in identification as well as authentication of the plant under study.
\end{abstract}

Keywords: Embelia ribes Burm. F, Proximate analysis, optimization studies, HPTLC.

\section{INTRODUCTION:}

A traditional medicinal system like Ayurveda effectively utilizes plants for prevention and treatment of variety of ailments. Medicinal properties of plants are due to their ability to synthesize variety of secondary metabolites [1]. The account of pharmaceutical utility of herbals is well documented in ancient treatise in Chinese, European and Indian traditional medicinal systems. Herbal based medicines are gaining acceptance worldwide. Global demand and consumption of crude plant material is also growing steadily. However plant based drugs exhibits complex chemical compendium which varies with geographical and environmental conditions. It has become imperative to develop a means to standardize the accepted quality control mechanism for herbals. WHO and other pharmacopoeias are coming up with guidelines for the evaluation of medicinal plants $[2,3,4]$. These guidelines serve as quality control benchmark for the evaluation of herbals. Proximate analysis, extractive values and optimization studies are such important quality control practices to be undertaken before phytochemical extraction of herbals. The methodologies are prescribed in various pharmacopoeias and WHO guidelines. HPTLC fingerprinting is accepted by WHO and all the pharmacopoeias as a tool for phytochemical investigation. HPTLC fingerprints are also employed for authentication, identification and checking adulteration.

Embelia ribes Burm. F, is a shrubby creeper of woody climber, belonging to family Primulaceae. It is an important medicinal found in semi-evergreen and deciduous forest in India. It is popularly known as Vaividang or Vavding. It is an important component of over the counter ayurvedic medicines like panchanimbadivati, sanjivanivati and chandraprabhavati. It is used for its rejuvenating property. It also exhibit anthelmintic [5] and antifertility activity $[6,7]$.

The present study deals with phytochemical analysis and chemical fingerprinting of EmbeliaribesBurm. F.

\section{METHOD AND MATERIAL:}

Dried fruits of Embelia ribes Burm. F were collected from Sindhudurg District, Maharashtra State, India and identified at The Department of Botany, RTMNU, Nagpur. The plant material was macerated 
and stored in an air tight container for further investigations.

Proximate analysis

Analysis of foreign organic matter, total ash content, acid insoluble ash, water soluble ash, sulphated ash, loss on drying and determination of crude fibres was performed as per the methodologies mentioned in Ayurvedic Pharmacopoeia of India $[8,9]$.

\section{Optimization studies}

Extractive values in six solvents with varying polarity were determined. The solvent with maximum extractive value was chosen for optimization studies for calculating optimised amount of solvent required, duration of extraction and number of extraction cycles required for maximum yield $[8,9]$.

\section{HPTLC studies}

Methanol was chosen as the solvent on the basis of optimization studies. Sonicated samples were taken for the HPTLC studies. Best resolution was obtained in the solvent Toluene: Chloroform: Ethanol $14: 4: 1$ $\mathrm{v} / \mathrm{v} / \mathrm{v}) .2 \mu \mathrm{Lsample}$ was applied in 5 bands of $8 \mathrm{~mm}$ width with the help of Hamilton microsyringe (Switzerland). Linomat V applicator (S/N: 080222), CAMAG HPTLC Visualizer system (S/N 15503) and WIN CATS software was used for the studies. The bands were detected after derivatization in anisaldehydesulphuric acid reagent. Photodocumentation chamber (CAMAG Visualizer (S/N: 150503) was used to capture chromatogram under UV light at $366 \mathrm{~nm}$ and visible light. The scanning was done by CAMAG Scanner 4 (S/N: 170422) to record the Rf values by WIN CATS software.

\section{RESULTS AND DISCUSSION}

Proximate analysis

The shelf life of powdered herbals varies with the plant species. The efficacy of stored herbal sample may get depleted due to oxidation or contamination. Quality control of herbal samples by proximate analysis is accepted by WHO and other
Pharmacopoeias. Proximate analysis of plant sample under study is given in table 1 . The value of proximate analysis was well below the prescribed limits of (API, 2000).

\section{Optimization Studies}

Results of optimization studies are summarized in Table 2. Methanol was found to be the best solvent based on its extractive value. The optimized amount of solvent for the extraction of $1 \mathrm{gm}$ of dried sample was $75 \mathrm{~mL}$ in two cycles of $90 \mathrm{~min}$.

HPTLC studies:

$2 \mu$ LMethanolic sample of Embelia ribes Burm. F developed in Toluene: Chloroform: Ethanol (4:4:1 $\mathrm{v} / \mathrm{v} / \mathrm{v}$ ) gave a good fingerprint after derivatization in anisaldehyde sulphuric acid reagent at $366 \mathrm{~nm}$ and visible light. The chromatograms are given in figure 1 and 2 .

\section{CONCLUSION:}

The proximate analysis of plant can be used as an important quality control parameter for determining the purity of crude samples for drug preparation. The optimized extraction studies will helpful in ensuring maximum extraction of the crude drug. HPTLC fingerprint which will serve the purpose of identification and authentication of the plant.

\section{REFERANCE :}

Amit Saraf, AparnaSaraf and AlkaChaturvedi,"Phytochemical Analysis and Chemical Fingerprinting of Seeds of Abrusprecatorius L.," ChemSci Trans.,2018,7(1), pp 63-70 DOI:10.7598/cst2018.1460

Asolkar LV et al, Second supplement to glossary of Indian Medicinal plants with active principles, CSIR, New Delhi, 1992, ;179

Ayurvedic Pharmacopoeia of India (API, Part I, Vol. IX, 2016)

(http://ayush.gov.in/sites/default/files/Ayurv edic\%20Pharmacopoeia\%20of\%20India\%20par t\%201\%20volume\%20IX.pdf)

ChaudhuryMR,Chandrasekaran R, Mishra S, Embryotoxocity and teratogeniscity studies of an ayurvedic contraceptive-pipliyadivati, J Ethnopharmacol, 2001,74(2), 189-193.

http:/ / www.ayurveda.hu/api/API-Vol-2.pdf 
IHP, 2002; The Ayurvedic Pharmacopoeia of India, 2000

Kholkute SD, Kekere MB, Munshi SR, Anti-fertility effects of the fruits of P.longum in female rats, Indian J ExpBiol, 17, 1979, 289-290.

Saraf, A. A., \&Shinde, P. S. (2018).Chemical fingerprint profile of various secondary metabolites of medicinal plant Derris heyneana (Wight and Arn) Benth. Research Journal of Pharmacognosy and Phytochemistry, 10(2), 193-199.

Saraf, A., \&Saraf, A. Phytochemical and Antimicrobial Studies of Medicinal Plant Piper longum Linn. International Journal of Pharmacognosy and Phytochemical Research, 2014, 6(2), 213-222.

Saraf, A., Srinivas, K. S., \&Chaturvedi, A. Phytochemical and Elemental Profile of Embeliaribes Burn. F. RESEARCH JOURNAL OF PHARMACEUTICAL BIOLOGICAL AND CHEMICAL SCIENCES, 2016, 7(4), 471-476.

Table 1: Proximate analysis of dried fruit of Embelia ribes Burm. F

\begin{tabular}{|c|l|c|}
\hline Sr. No. & \multicolumn{1}{|c|}{ Parameter } & $\begin{array}{c}\% \\
\text { content }\end{array}$ \\
\hline 1. & Foreign organic matter & 0.63 \\
\hline 2. & Total ash & 10.33 \\
\hline 3. & Acid insoluble ash & 1.17 \\
\hline 4. & Water soluble ash & 4.67 \\
\hline 5. & Sulphated ash & 6.33 \\
\hline 6. & Loss on drying & 6.07 \\
\hline 7. & Crude fibre content & 25.8 \\
\hline
\end{tabular}

Table 2: Optimization studies of dried fruit of Embelia ribes Burm. F

\begin{tabular}{|l|l|l|l|l|}
\hline Sample & $\begin{array}{l}\text { Type of } \\
\text { solvent }\end{array}$ & $\begin{array}{l}\text { Amount } \\
\text { of } \\
\text { solvent }\end{array}$ & $\begin{array}{l}\text { Time for } \\
\text { extraction }\end{array}$ & $\begin{array}{l}\text { Number of } \\
\text { extraction }\end{array}$ \\
\hline $\begin{array}{l}\text { Dried } \\
\text { fruits of } \\
\text { E. ribes }\end{array}$ & Methanol & $75 \mathrm{~mL}$ & $90 \mathrm{~min}$. & 02 \\
\hline
\end{tabular}

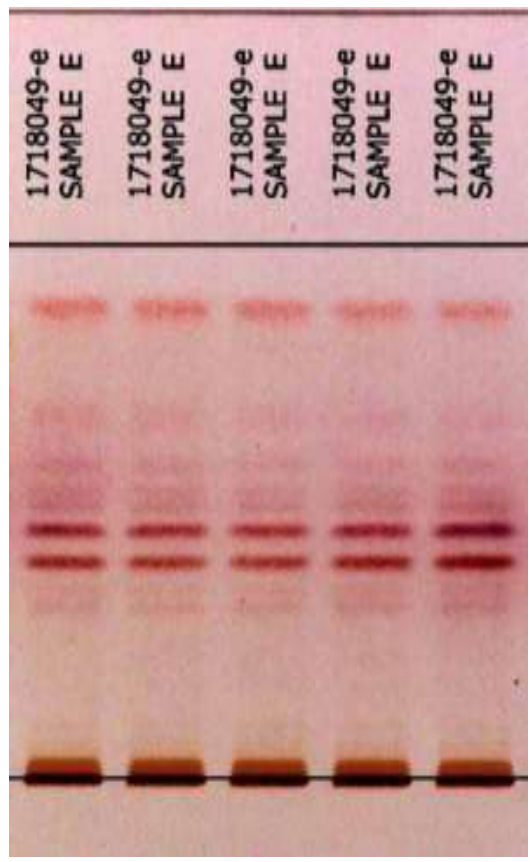

$540 \mathrm{~nm}$ (after derivatization)

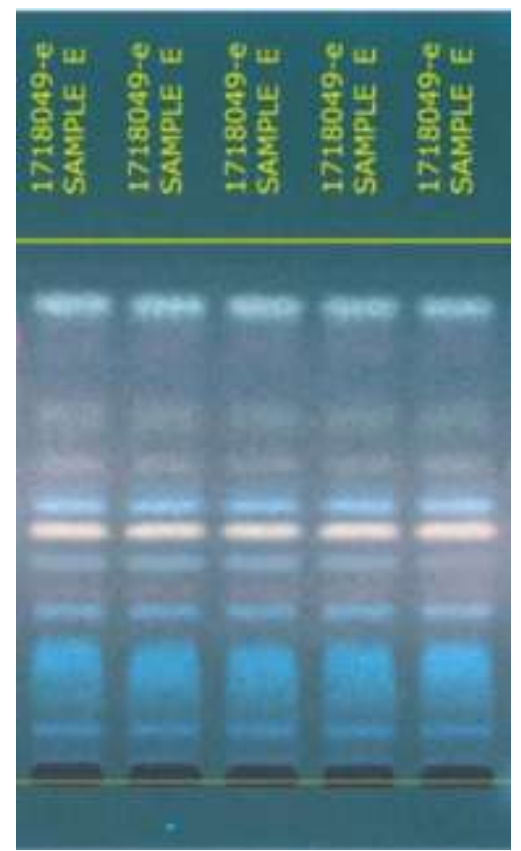

$366 \mathrm{~nm}$ (after derivatization) 